Students' Attitudes Toward Learning Statistics with R Alyssa Counsell 1 \& Robert A. Cribbie2

1 Department of Psychology, Ryerson University, Toronto, ON, Canada

2 Department of Psychology, York University, Toronto, ON, Canada

Accepted by Psychology Teaching Review

* Correspondence should be addressed to Alyssa Counsell, Department of Psychology, Ryerson University, Toronto, ON, Canada, M5B 2K3 (e-mail: a.counsell@ryerson.ca) 


\begin{abstract}
Statistics plays an important role in psychology, but statistics modules are notoriously unpopular amongst psychology students. We examined attitudes toward statistics and attitudes toward the statistical software package $\mathrm{R}$ in both undergraduate and postgraduate students across the duration of a statistics module. Participants' responses were analyzed using both quantitative and qualitative techniques. Results demonstrated that, on average, students in introductory level modules held neutral (not negative) attitudes, but students at higher study levels held somewhat positive attitudes towards $\mathrm{R}$ and statistics. While not all students enjoyed learning $\mathrm{R}$, our findings demonstrate that many students enjoyed statistics or R, most students found statistics/R valuable and they generally reported feeling competent using software by the end of their module. These results challenge the argument that $\mathrm{R}$ is not suitable for undergraduate psychology students. Consequently, benefits, challenges, and implications of teaching R to psychology students are discussed.
\end{abstract}




\section{Student Attitudes Toward Learning Statistics with R}

Statistics modules are among the most problematic for students in psychology (Murtonen, Olkinuora, Tynjälä, \& Lehtinen, 2008). A number of research projects investigating students’ experiences with, and attitudes toward, their statistics modules suggest that students hold negative attitudes toward statistics (e.g., Conners, McCown, \& Roskos-Ewoldsen 1998; Hogg, 1991; Ruggeri, Dempster, Hanna, \& Cleary, 2008; Schutz, Drogosz, White, \& Distefano 1998). Further, research suggests that students tend to have little interest and motivation in taking statistics and methodology modules compared to content modules (Rajecki et al., 2005) and that the majority of students will take only the required statistics modules and avoid taking them as long as possible (Onwuegbuzie, 2004). A leading theory about students' fear or dislike of statistics stems from a lack of motivation, enthusiasm, and interest (Gal \& Garfield, 1997). Learning theory research suggests that individuals learn and perform best in modules where they feel that the material has value and that they are able to succeed in the module (e.g., Eccles, 1983; Eccles \& Wigfield, 2002).

Given the importance of statistics in psychology, it is worthwhile to examine students' attitudes toward statistics. Aside from understanding what kinds of attitudes students hold, numerous studies have found that more positive attitudes toward statistics tend to be associated with higher grades (e.g., Chiesi \& Primi, 2009; Dempster \& McCorry, 2009). Attitudes toward statistics can be assessed using a few different domains; specifically, the four most commonly researched are: i) affect; ii) cognitive competence; iii) value; and iv) difficulty (Emmioğlu \& Capa-Aydin, 2012). In their meta-analysis which included 17 studies, Emmioğlu and CapaAydin found that these four domains of statistics attitudes were consistently associated with module performance, but affect and cognitive competence were more strongly related to higher 
grades than value and difficulty. They also noted large differences in effect sizes, whereby studies from the United States had effect sizes approximately double those of other countries.

An important limitation of the statistics attitude literature is that most samples only include undergraduate students taking an introductory level statistics module. Few studies have investigated attitudes in students taking statistics modules later on in their degrees. One exception is Walker and Brakke's (2017) research, which compared student attitudes across an introductory and advanced undergraduate module. In their sample of women in a historically Black college in the United States, attitudes toward statistics were slightly positive. They found differences between the modules such that attitudes in the advanced class were significantly higher at the beginning of the semester, but not at the end - whereby attitudes were, on average, somewhat positive in both the introductory and advanced classes. Of the work that has investigated postgraduate students' experiences with statistics, the focus tends to be more on statistics anxiety than other attitudinal domains (e.g., Onwuegbuzie, 2004; Onwuegbuzie \& Wilson, 2003). The limited literature into statistics attitudes of students past introductory level statistics has important implications for the theory that students dislike statistics due to lack of interest or because they do not see the value of statistics. Given the important research role of statistics for advanced students (undergraduate and postgraduate level), their attitudes toward statistics may be more positive than those of students in introductory level statistics modules.

\section{Software Use in Psychology}

Regardless of study level, one way in which statistics modules may be more useful or valuable to students is when the module helps students build a concrete skill such as using statistical software (Hernández, 2006). In fact, according to the Guidelines for Assessment and Instruction in Statistics Education (GAISE; 2016), the biggest change (and recommendation) in 
teaching statistics from the previous decade was the increased use of technology and software in statistics modules. Despite this recommendation, the incorporation of statistical software in introductory statistics modules in psychology varies widely. For example, Davidson et al. (2019) found that only half of introductory statistics modules in Canadian universities use some form of statistical software. Specifically, SPSS was the most popular, followed by Excel and then the open source software R (R Core Team, 2018). In postgraduate level statistics modules, most still use SPSS, but R is the second most popular choice (Davidson et al., 2019).

Choice of software in statistics modules remains a somewhat contentious discussion for instructors (see e.g., Ward, 2013). Some argue that syntax-based software like R is too complicated for students, particularly undergraduates. Others find the skills obtained while learning $\mathrm{R}$ and the advantages of teaching with $\mathrm{R}$ extremely valuable. Differences between the packages warrants brief discussion. SPSS has been popular in psychology for its easy-to-use point and click interface. The software is simple if users are familiar with spreadsheets like Excel, but it comes with some limitations that may account for its declining citations (e.g., (Muenchen, 2018). SPSS comes with licensing costs and has limited capabilities for incorporating novel methods. In contrast, $\mathrm{R}$ is free and open-source, allowing for quick inclusion of novel methods. Over the past few years, R package developers have made great strides to make the software more user friendly, including the more accessible interface, RStudio (RStudio, 2018), and numerous free, online resources and tutorials are available.

Despite the important role of software in statistics modules and research in psychology, research on the impact of statistical software on students' grades and learning is notably absent from the teaching of psychology literature. One study investigated using SPSS and found mixed results about its effect on grades and students' attitudes toward statistics in an undergraduate 
statistics module in an Indonesian university (Jatnika, 2015). Specifically, Jatnika found that after using SPSS for the duration of the module, students felt that their knowledge and skills in statistics increased but their grades actually decreased. Another example is the work of Brezavšček, Šparl, and Žnidaršič (2017) who examined the use of SPSS in psychology modules at a Slovenian university. They found that various attitudes domains (e.g., self-efficacy, statistics anxiety, value of SPSS and perceived ease of use) predicted students' intentions to use SPSS in the future. Brezavšček and colleagues did not examine how these constructs were related to students' achievement in the module though. Rode and Ringel (2019) examined differences in anxiety toward interpreting R or SPSS output in introductory statistics modules. They found that while R output initially produced more anxiety than SPSS output, the differences disappeared by the end of module, suggesting that students are able to adapt to R equally well as they do to SPSS. Note that the students in the Rode and Ringel (2019) study did not learn how to use either of the software packages though. Consequently, research into psychology students' attitudes and experiences with software remains understudied.

\section{Study Rationale}

The current study investigates attitudes toward statistics and statistical software in modules using $\mathrm{R}$ in a diverse student sample taking a statistics module in psychology. This project makes two important contributions to the literature on statistical attitudes in psychology. First, although statistics is a required module in the vast majority of psychology programs (Aiken, West, \& Millsap, 2008; Counsell, Cribbie, \& Harlow, 2016; Stoloff et al., 2010), attitudes toward statistics and attitudes toward statistical software is an understudied topic, particularly in North America. Further, a limitation of work in this area is that most of the research has focused on undergraduate students taking an introductory statistics module. Our 
study adds to the literature by including a Canadian sample of undergraduate students in introductory statistics modules and advanced statistics modules, along with postgraduate students taking required statistics modules. Secondly, our study further contributes to the psychology teaching literature by: i) including qualitative information about students' attitudes toward and experiences learning statistics with R; ii) examining how attitudes toward $\mathrm{R}$ relate to more general statistics attitudes, and iii) examining whether students with more positive attitudes toward using $\mathrm{R}$ tend to also have a higher final grade in a statistics module.

\section{Research Questions}

Our project sought to answer the following research questions:

1) What is the valence of students' attitudes toward statistics and technology at the beginning and at the end of statistics modules that use R, and is there a significant change in attitudes?

2) What is the magnitude of attitudinal differences toward statistics and technology between first year undergraduate students, upper year undergraduate students, and postgraduate students?

3) To what extent are attitudes toward learning R related to other attitudes toward statistics?

4) What are students' experiences with and attitudes toward learning statistics with R?

5) Does holding more positive attitudes toward R predict a higher final grade in a statistics module?

It was anticipated that postgraduate students would hold more positive attitudes toward statistics and statistical software compared to undergraduate students, but that generally attitudes would be slightly negative. We further hypothesized that students with more positive attitudes toward learning $\mathrm{R}$ will receive higher grades in their statistics module (after controlling for GPA, study level, and previous exposure to R). We did not have any specific hypotheses about the 
types of qualitative information students would provide regarding their experiences learning statistics with R.

\section{Methods}

\section{Participants}

The study included a total of 244 participants. All participants were students taking a one-semester statistics module in psychology at a large multi-cultural university in Toronto, Canada. Participants included 157 (64\%) students from one section of an entry level undergraduate statistics module, 37 (15\%) students from one section of an upper year (advanced) undergraduate statistics module, and 50 (20.5\%) came from three sections of first year postgraduate level statistics modules. These five statistics modules represented the only psychology statistics modules in the academic year that incorporated the statistical software package $\mathrm{R}$ into lectures, labs, and/or assignments. Consequently, all students from each module were invited to participate. Each of the different statistics modules was a degree requirement for most study participants. The exception was the advanced undergraduate module which was required for students interested in an honours degree in psychology, but was not required for general psychology majors. Assessments for all of the modules included a combination of exams and written assignments or labs.

The majority of participants were psychology majors, although the introductory level statistics module had 27 students with other related majors (e.g., biology, kinesiology, nursing, health sciences, criminology, sociology, etc.). Of the 185 participants who reported their sex, approximately $75 \%$ were female. The median age in the sample was 21 years $(S D=5.27)$, but as expected, age was related to study level whereby postgraduate students' median age was 25 
years $(S D=4.10$, range: $22-39)$ and undergraduate students' median age was 20 years $(S D=$

5.21, range: $18-56)$.

\section{Procedure}

All of the students in each of the five modules were given a survey asking questions about their attitudes toward statistics and statistical software, engagement in the module, and demographic information during class time. The survey was completed twice, - once on the first day of class, and again on the last day of class. Students were given 15 minutes to complete a paper copy of the survey at each time point. The questions on the survey at time 2 were identical to those at time 1 , but included some additional questions that could not be asked at time 1 (i.e., about their experiences with the statistical software used in the module). At time 2, participants were also asked open-ended questions where they could include further information about their attitudes toward statistics and $\mathrm{R}$ as well as describe elements of the module that were helpful. Across the different modules, approximately $83 \%$ of the students participated in at least one time point.

Ethics approval was obtained from the institutional Research Ethics Board and student participation was completely voluntary. Participation in the survey was anonymous to the instructors and researchers, who were not present in the room while students completed the surveys. Research assistants completed the coding and data entry to ensure anonymity of the participants from the researchers and instructors. Final grade information was obtained from module instructors. Initially we sought to include final grades for postgraduate students to answer our fifth research question, but we decided against it for two reasons: 1) postgraduate level module instructors provided grades on different metrics (e.g., letter vs. numeric) and 2) postgraduate final grades had very little variability. 


\section{Materials}

Survey on Attitudes toward Statistics (SATS). The SATS (Schau, 2003) is a 36-item scale with Likert items assessing attitudes toward statistics among students currently taking a statistics module. The original 28-item scale (Schau et al., 1995) measured attitudes across four domains, whereas the revised version includes six subscales. While correlated with one another, the subscales measure different domains and therefore a single total score for the scale should not be used. The subscales are: i) affect: feelings concerning statistics; ii) cognitive competence: perceptions of students' own intellectual knowledge and skills in statistics; iii) value: the value or worth attributed to statistics in students' personal and professional lives; iv) difficulty: the perceived difficulty of statistics; v) interest: students' level of individual interest in statistics; and vi) effort: the amount of work students expend to learn statistics (Schau et al., 2003). Each item is rated on a 7 point scale expressing the degree with which the student agrees or disagrees with the item. Half of the items are negatively worded and must be reverse coded to compute subscale scores. Higher scores on the subscales reflect a more positive attitude toward that domain with the exception of difficulty, where higher scores reflect perceiving statistics as easier.

The SATS has been found to have good convergent validity with other similar scales, good reliability, and research has supported the factor structure proposed (see Nolan, Beran, \& Hecker, 2012 for a review). In our sample internally consistency for each subscale was assessed using Cronbach's alpha ( $\alpha$; Cronbach, 1951) and McDonald's Omega ( $\omega$; McDonald, 1970; 1999). Cronbach's $\alpha$ for the attitudinal domains of affect, cognitive competence, value, and interest at time 1 were at least .85 , and at time 2 , they were at least .81 . McDonald's $\omega$ values were all closer to .90 for these subscales at time 1 and time 2 with the exception of value at time 2 which was .75. Effort and difficulty demonstrated poor internal consistency using $\alpha$ with 
values of .56 and .64 , respectively, at time 1 and .72 and .69 , respectively, at time 2 . Coefficient $\omega$ was a little higher but inconsistent across time with effort being .57 at time 1 and .77 at time 2 and difficulty being .77 and .80 . Because of the lower reliability scores and extremely skewed distributions of the effort and difficulty subscales, we decided against including them in our analyses.

Students' Attitudes toward Statistics Technology Scale (ATST). The ATST is a 28-item scale measuring attitudes toward statistics and statistics technology. Like the SATS, a total score should not be computed because subscales measure attitudes toward different domains. The ATST measures attitudes within five domains; i) statistics cognitive competence: students' attitudes toward their own knowledge and skills in statistics; ii) technology cognitive competence: students' attitudes toward their own knowledge and skills using technology such as computers; iii) attitudes toward learning statistics with technology; iv) value: perceived value of statistics for students' personal and professional life; v) affect: general attitudes toward statistics (Anastasiadou, 2011). Each of the items is measured on the same scale as the SATS, i.e., a 7 point Likert scale ranging from "strongly disagree" to "strongly agree." The original author reported satisfactory reliability scores $(\alpha)$ for the five domains. In our sample, Coefficients $\alpha$ and $\omega$ were around .90 at both time 1 and time 2 for all subscales except for value which was between .75 and .85 across the time points. Given that affect, statistics cognitive competence, and value are the same constructs as those in the SATS, we do not include them in our results to avoid redundancy.

We will make the full results of all subscales of both the SATS and ATST available on request. Attitudes Toward R (ATR). Given that a major goal of the study was to investigate attitudes toward the statistical software $\mathrm{R}$, we derived questions specific to $\mathrm{R}$ that were similar in nature to 
the questions in the previous measures. These questions are included in Appendix A. Each item is rated on the same 7-point scale used in the SATS and ATST. Cronbach's $\alpha$ for these items in our sample was .92 and McDonald's $\omega$ was .95.

\section{Results}

To answer our research questions, we used a mixed methods data analytic strategy. We present descriptive and inferential statistics to analyze information about attitudes toward statistics, technology, statistical software, and final grades (research questions 1, 2, 3, and 5). We also include qualitative information from a thematic analysis on the open-ended questions about attitudes toward and experiences with learning statistics with $\mathrm{R}$ (research question 4).

\section{Missing Data}

Missing data at the item level was generally not a problem. Few participants failed to answer questions and the data that were missing appeared to be missing completely at random (e.g., one participant missed the back of one page on the survey, another missed a single question in a survey). Participants with missing data on more than two items on a given subscale (e.g., affect on SATS) did not receive a composite mean score for that subscale ( $n=7$ at Time 1 and $n$ $=2$ at Time 2). However, there was a large amount of missing data when combining the data for both time points. Despite having a total of 244 participants with data, we had 104 participants with data at both time points (42.6\%), 83 with Time 1 data only (34.0\%) and 57 with Time 2 data only $(23.4 \%)$. Final grades were missing for 60 participants $(24.6 \%)$, with the main reason for missingness being that the student dropped the class $(N=52)$. Further, dropping the class was the main reason that other data were missing at Time 2 . The reason for missing grades in the eight participants who did not drop the class was either due to unreadable handwriting such that the research assistants could not properly read the participant's name or were unknown (e.g., 
grade may have been deferred). All of the participants who dropped the class were undergraduate students. The largest mean attitudinal difference between those who dropped or did not drop the module was on the ATST technology cognitive competence subscale, $M_{\text {diff }}=.33$ (out of 7). The small magnitude of the difference led us to interpret that the students who dropped the module likely did not drop because they had significantly worse attitudes toward statistics.

\section{Research Questions 1 and 2: Attitudes Toward Statistics and Technology}

To answer our first two research questions, we examined mean scores on the various attitudinal measures by study level, i.e., introductory undergraduate, advanced undergraduate, and postgraduate at each time point. This information is presented in Table 1.

Across the different attitudinal domains, introductory level undergraduate students tended to hold neutral as opposed to negative attitudes toward statistics and software (means close to 4 the midpoint of the scale). Their affect scores were closer to 3.5 suggesting that they slightly dislike statistics, but their interest scores were at or slightly higher than the midpoint (4 to 4.5 across time). They did, however, somewhat value statistics as the mean value score is above the midpoint of the scale (e.g., 4.59). Upper year undergraduates and postgraduate students, on average, tended to hold somewhat positive attitudes toward statistics, as demonstrated by scores above the midpoint of the 7 point scale across all domains. This pattern was observed for both time 1 and time 2 scores. These results do not support the hypothesis that students hold particularly negative attitudes toward statistics.

Generally, participants from higher levels of study held more positive attitudes toward statistics and R compared to those at lower study levels and demonstrated less variability in scores - a finding that supports our second research hypothesis. Specifically, students in the introductory undergraduate level statistics module had an almost 1-point (out of 7) lower score 
on measures like affect, value, interest, and cognitive competence compared to upper year undergraduates and postgraduate students. This effect held across both time points. Somewhat surprisingly, the postgraduate student and advanced undergraduate participants had similar scores across most of the attitude domains. Further, by the end of the module, students (on average) from all levels held relatively positive attitudes towards learning statistics and R.

\section{Research Question 3: Correlations between R Attitudes and Other Statistical Attitudes}

Unsurprisingly, the statistical attitude and software attitude domains were highly correlated with one another. Figure 1 includes a visual representation of a correlation matrix with the relevant statistics attitude domains and the ATR composite variable. Of note is that few attitudes domains at Time 1 were highly correlated with ATR. Specifically, only the value and interest domains on the SATS included correlations with ATR above $.3(p<.01)$. The relationships between the different attitude domains and ATR at Time 2 told a different story though, whereby the correlations were all greater than .3. In fact, most of the correlations were closer to .5 or .6 suggesting a strong relationship between ATR and affect, interest, value, and cognitive competence at the end of a statistics module in psychology. These results suggest that different types of attitudes toward statistics and software are interrelated.

\section{Research Question 4: Student Experiences with Learning Statistics with R}

Of the participants who filled out the survey at Time 1 (i.e., $n=185), 77(41.6 \%)$ had heard of R but only 31 participants $(16.8 \%)$ had used it before taking the class. Most of the students who had used $\mathrm{R}$ before were postgraduate students $(N=23)$. Because most participants had not heard of $\mathrm{R}$ at the beginning of the study, we have information regarding their attitudes toward $\mathrm{R}$ at time 2 only. 
Thematic analysis. To help understand how students viewed their own experiences with learning statistics and R, we conducted a thematic analysis (e.g., Braun \& Clarke, 2006) of responses from three open-ended questions: 1) Now that you've completed the course [module], do you feel that your attitudes towards statistics and statistical software changed? If so, how have they changed?; 2) Thinking about your experiences in this statistics course [module], what would you say are the factors that most influenced your attitudes towards statistics and statistical software? Be sure to distinguish between factors that positively influenced your attitudes and factors that negatively influenced your attitudes; and 3) Any other comments or feedback relevant to statistics and statistical software? Of the 161 participants with Time 2 data, 134 answered at least one of the open-ended questions. Of the participants for whom we had qualitative data, $79(59 \%)$ were undergraduates in the introductory module, $20(15 \%)$ were undergraduates taking the advanced module, and 35 (26\%) were postgraduate students.

The qualitative analysis occurred in multiple steps. First, the authors read the open-ended responses to get a sense of what was reported. The responses were then read again, and lower level themes were coded, and each theme was tallied across different participants. For example, if someone answered that the instructor positively impacted their attitudes in question 1 , but then provided more information about exactly how the instructor impacted their attitudes in question 2 or 3 , all of the information would be coded into the theme of "positive impacts of instructor" with a frequency count of 1 . This coding scheme was chosen so that individuals who wrote more detailed responses on the same topic did not end up having more influence on the final reporting of theme frequency. The authors then did a second and third reading of the responses at a later time to ensure that important themes were not missed or to reassess the fit of themes. Seventy unique lower level themes were included and frequencies of participants' responses for each 
theme were tallied based on whether the participant was an undergraduate student or postgraduate student. This information is included in Appendix B.

The lower level themes were then condensed further such that our final analysis included eight higher-order themes capturing the experiences of students taking a statistics module in psychology. The themes included: 1) Degree of Comfort and Competence; 2) Instructor and Resources; 3) Degree of Enjoyment; 4) Degree of Difficulty, 5) Value of Statistics and R; 6) Learning Trajectory, 7) Impact of previous experiences or expectations; and 8) Importance of Critical thinking. Note that within each of these eight themes, some students may have stated that the experiences negatively contributed to their attitudes whereas other students may have said that the experiences positively contributed to their attitudes. These themes, their valence, and their frequencies are captured in Table 2.

Despite the themes capturing both negative and positive experiences, four times as many students commented on high or increased competence/confidence as those who stated low competence or confidence. Further, eight times as many students stated outright that learning statistics or R was valuable as though who stated that it was not valuable. Negative valence of the enjoyment and difficult themes was higher than positive experiences though. For example, 52 students stated that they did not like or enjoy statistics/R compared to 43 who reported enjoying learning statistics or using $\mathrm{R}$. This finding is corroborated by two quantitative questions, one asking students to rate their attitudes toward statistics, and another to R specifically. Average responses for introductory level undergraduates were neutral $(M=4.2$ out of 7 on both questions), whereas upper year undergraduates had slightly positive attitudes toward both statistics $(M=4.7)$ and $\mathrm{R}(M=4.6)$. Postgraduate students reported positive attitudes $(M=5.2$ on 
both). Similarly, 52 students rated learning statistics/R as difficult compared to 41 who reported that statistics or R was not as difficult as they anticipated.

Half of the qualitative themes mapped onto the four original SATS attitude domains i.e., competence/confidence, enjoyment (affect), difficulty, and value. Themes such as the importance of instructor and peer resources, comments on personal learning styles or trajectories, critical thinking, and previous experience did not map onto the attitudinal domains in the quantitative measures. This finding is important because students overwhelmingly reported that the module instructor or teaching assistant positively impacted their attitudes toward learning statistics or R. On the other hand, students who mentioned previous experiences with statistics were more likely to describe negative than positive experiences. Implications of the thematic analysis results will be elaborated further in the discussion. Lastly, to help provide more information about the types of comments that were coded into the themes, Table 3 includes direct quotation prototypical examples.

Statement of Reflexivity. In constructing the themes from the open-ended questions, it is important to acknowledge our positionality in the research topic. Both authors are statistics instructors; however, the first author was also a $\mathrm{PhD}$ student at the time of data collection/analysis. Accordingly, our perspective aligned with desires for positive changes/experiences in attitudes toward statistics and $\mathrm{R}$, feeling that we had a personal investment in the module results. Consequently, we reminded ourselves of this position, bracketed our thoughts during the coding process, and purposely sought evidence that falsified these views. In fact, we approached the thematic analysis as a learning experience to help us, as instructors, better understand the experiences of the participants to further support our future 
students. Lastly, embracing a more constructionist epistemology further allowed us to separate our realities as instructors with the realities and experiences of the participants.

\section{Research Question 5: Predicting Final Module Grade for Undergraduate Students}

We hypothesized that positive attitudes toward learning R (ATR) would be related to higher final grade in undergraduate statistics classes after controlling for important covariates. The first covariate was overall GPA since students with higher GPAs are likely to have a higher final grade in their statistics course as well. Given that we had data from two different classes of undergraduates, one introductory level ( 2 nd year module) and one advanced level (4th year module) we also include study level (i.e., introductory vs. advanced) as a covariate. Lastly, we also include whether the student has used $\mathrm{R}$ before taking the module to help control for previous exposure to using the software. These three covariates and ATR accounted for a statistically significant proportion of variance in final grade, $F(4,88)=20.45, p<.001, R_{2}=.48$. Information about the impacts of each predictor in the regression model are presented in Table 4. One can see that even after controlling for study level, overall GPA, and previous use of R, ATR is a significant predictor accounting for $5.1 \%$ of the unique variance in final grade. In our sample, an increase of 1 point on the ATR scale (out of 7) is associated with a final grade increase of $2.34 \%$ controlling for study level, GPA, and previous use of R. In fact, attitudes toward R appears to be as strongly associated with the statistics module final grade as overall GPA since both predictors demonstrate similar standardized regression coefficients and semi-partial squared correlations.

\section{Discussion}

The current study examined attitudes towards statistics and statistical software in students currently taking a psychology statistics module that incorporated the statistical software package, R. Participants included students at various study levels, i.e., students in an introductory 
undergraduate module, advanced undergraduate module (third- or fourth- year students), and postgraduate students. This study is one of few that examined attitudes toward statistics in students taking non-introductory statistics modules and one of the first to examine attitudes toward the statistical software package $\mathrm{R}$ in students taking a statistics module in psychology.

\section{Rethinking the Idea that Psychology Students Simply Don't Like Statistics}

A fair amount of literature on attitudes toward statistics or teaching statistics focuses on the assumption that students are not interested in and do not like or value statistics in the social sciences (Conners et al., 1998; Hogg, 1991; Rajecki et al., 2005; Ruggeri et al., 2008; Schutz et al., 1998). Our results introduce some skepticism into this assumption. While undergraduates in introductory statistics modules, on average, reported slightly negative affect toward statistics and $39 \%$ reported disliking statistics or $\mathrm{R}$ in open-ended questions, the rest of their attitudinal domains were neutral or even positive. In fact, at the beginning of their module, they reported some interest in statistics and rated it as somewhat valuable (mean scores around 4.5/7 for both domains). Further, students taking more advanced statistics modules in psychology (either undergraduate or postgraduate level) actually held positive scores, on average, across all of the statistical attitude domains. Surprisingly, there were few differences in attitudes between advanced undergraduate students and postgraduate students. In the open-ended questions, $32 \%$ of participants reported liking or enjoying statistics/R, $50 \%$ of students reported feeling confident or competent with statistics or R, and $37 \%$ stated that they found statistics to be valuable. While these numbers are not the majority, it is important to remember that students were not asked about these domains specifically; they were asked to describe their experiences and the factors that led to positive or negative attitudes. The fact that many students did not mention some of these experiences may mean that they held neutral (i.e., not positive or negative) experiences, but 
this cannot be verified. Average scores on quantitative measures asking students to rate their attitudes toward statistics resulted in scores that were neutral for introductory level undergraduates, slightly positive for upper year undergraduates, and somewhat positive for postgraduate students. The observed attitudinal differences across study level lends support to the argument that more exposure to statistics is associated with more positive student attitudes. Our findings mirror the results of Walker and Brakke (2017), and may also support Bond, Perkins, and Ramirez's (2012) finding that introductory level students tend to have initially rudimentary or inaccurate perceptions of statistics, but that their perceptions improve with exposure.

\section{Teaching Students R in Psychology Statistics Modules}

Looking at the average scores on the quantitative items measuring attitudes toward using R specifically, it was encouraging that students, on average, held positive attitudes toward using $\mathrm{R}$ across all levels of study (average module scores ranging from 4.43 to 5.42 out of 7 ). Further, when students were asked whether they became more comfortable with $\mathrm{R}$ during the module, $85 \%$ chose 4 or higher, while $53 \%$ chose 6 or 7 . When students were asked whether they thought $\mathrm{R}$ would be useful for their future, $78 \%$ chose 4 or higher, while $48 \%$ chose 6 or 7 . More students than expected reported enjoying learning and using $\mathrm{R}$, found $\mathrm{R}$ useful, and stated that $\mathrm{R}$ helped them learn statistics and think critically about data analysis.

There were some students though, particularly undergraduates in introductory modules, who stated that $\mathrm{R}$ was too advanced for the purpose of the module, who found it too difficult, or who stated they would have preferred using hand calculations over statistical software. It appeared that students in these categories were individuals who were not interested in research, noted that the module was a requirement and not one they would have taken otherwise (based on 
quantitative questions requesting this information and their open-ended responses), or who stated they will never need to use anything from the statistics module again. These results suggest that negative attitudes tend to come from individuals who perceive that they will not need to use statistics concepts or software in their current or future work. Perhaps focusing on the benefits of building skills relevant to industry (e.g., programming and critical assessment of tables and graphs in the media) could help improve attitudes among students with less interest in research and academia.

On the whole, learning $\mathrm{R}$ was generally a more positive than negative experience for students. While more students stated outright that they did not enjoy $\mathrm{R}$ in the qualitative themes (39\%), a large number stated that they enjoyed learning $\mathrm{R}$ as well $(32 \%)$ and $29 \%$ did not describe whether they enjoyed or did not enjoy it. Learning $\mathrm{R}$ could be described as positive in other qualitative themes such as competence/confidence, value, and positive impacts of module instructors too. A number of students noted that R had a steep learning curve or had initially caused them some stress, anxiety, or frustration, but they were able to overcome these challenges, and even enjoy using it by the end of the module. In fact, several students expressed interest in wanting to learn more about using $\mathrm{R}$ or seeking out additional opportunities to use and learn it. These results corroborate the findings of Rode and Ringel (2019) and challenge the widely held beliefs that $\mathrm{R}$ is too difficult for students and that they will not find it useful moving forward.

Lastly, our regression analysis demonstrated that even after controlling for study level, overall GPA, and having used R prior to taking the module, more positive attitudes toward $\mathrm{R}$ was associated with a higher final grade in a statistics module in our undergraduate sample. Our results demonstrate that student attitudes are associated with module performance, lending 
support to a number of studies with similar findings (e.g., Harlow, Burkholder, \& Morrow, 2002; 2006; Ramirez, Schau, \& Emmioglu, 2012; Ruggeri et al., 2008, Sizemore \& Lewandowski, 2009).

\section{Considerations for Instructors}

We hope that this project serves as evidence for instructors who are hesitant to incorporate $\mathrm{R}$ into their statistics modules for fear that it is too difficult for students and that they will not want to learn it. There are some important considerations, however, in helping facilitate the transition. Our qualitative data showed that the two most common themes for impacting students learning of both statistics and R was their instructor (and teaching assistant) and their own feelings of competence. As such, engaged and passionate instructors have the potential for a large impact in such modules. This is likely true regardless of whether and what software is incorporated into a statistics module. To help students build competence, it is important to design assessments and exercises that help build up to more difficult tasks in R slowly to help ease the transition or learning curve. Giving students opportunities to make mistakes early and learn from them in a low-stakes environment will help alleviate the initial stress of using a more difficult tool and allow them to build up a level of competence by the end of the module. Other themes that emerged were previous experiences and personal learning trajectories. Of the students who mentioned previous experiences or expectations, their responses tended to be negative more often than positive (e.g., believing they are not good at math/stats). It is therefore recommended that instructors spend some time early in the module to address expectations and encourage students to try to approach the module with a "clean slate." Lastly, some students mentioned that there were out of class stressors that burned them out or made it difficult to do well in their 
statistics module. This theme is not specific to statistics modules but serves as a reminder for instructors to consider current challenges faced by students (e.g., financial burden).

Statistical software is a necessary skill to conduct research and analyze data in psychology. We further argue that fostering competence and positive attitudes toward statistics and statistical software will help improve the state of psychological science. For this reason, it is important that students and researchers in psychology receive sufficient training and statistical skills (e.g., Aiken et al., 2008; Counsell et al., 2016). With current open science initiatives suggesting sharing data and open source code (e.g., Kubilius, 2014), learning R is becoming an increasingly useful skill for postgraduate students and researchers. We further argue that by teaching a tool like $\mathrm{R}$ to undergraduates we are aiding in their professional development for careers within and outside of academia.

\section{Limitations and Future Directions}

There were several limitations to the current research. Because all of the modules used the statistical software, $\mathrm{R}$, we did not have a comparison group. The implication is that we are not sure whether a student held positive attitudes toward R specifically or holds positive attitudes toward statistical software in general (i.e., realizing they do not have to do hand calculations). In the qualitative analysis, only four participants stated they would have preferred using a different statistical software package though. However, previous research from engineering suggests that learning a point and click software first (e.g., SPSS) negatively impacts students' use of syntaxbased software (e.g., R) later on (Yechiam, Erev, \& Parush, 2004).

Given the responses in some of the qualitative responses, examining participants' initial appraisals of statistics modules would be worthwhile. By this we mean, that differences on attitudes could be influenced by how students perceive their statistics module. Several students 
noted that they found the learning curve in $\mathrm{R}$ to be steep, but were able to overcome the challenge such that they no longer found $\mathrm{R}$ to be too difficult, and even came to enjoy using it. Other students found that $\mathrm{R}$ was too difficult and could not overcome the learning curve. It is possible that some students approached learning $\mathrm{R}$ as a challenge whereas others approached it as a threat. Future research on the topic is warranted.

Lastly, we recommend that future research focus on learning outcomes instead of grades. Future intentions to continue to learn and use the software, perceived competency, and knowledge of the module material may provide a more meaningful assessment of module impact and student attitudes. A further complication is that focusing on grade alone becomes difficult when examining students at different study levels because the grading norms vary greatly when comparing undergraduate to postgraduate students. In fact, this may be the very reason that research on attitudes toward statistics has focused almost exclusively on undergraduate students.

\section{Summary}

In conclusion, many students did not hold negative attitudes toward statistics or learning the software R in psychology statistics modules. Students with more experience with statistics (e.g., taking advanced modules or postgraduate students) tended to hold even more positive attitudes than students from introductory level modules. By the end of a statistics module, most students indicated that they became more comfortable with $\mathrm{R}$ and that they see the value of $\mathrm{R}$ moving forward. In fact, students generally rated statistical software as being useful or necessary in psychology. Results also support the importance of building more positive attitudes toward statistical software to help maximize students' module performance in undergraduate statistics modules. Lastly, students overwhelmingly commented that their instructor had a large influence 
on their experiences in the module, reinforcing the impact that statistics instructors have in shaping students' attitudes.

\section{Acknowledgements}

The authors gratefully acknowledge the contributions of research assistants, Nataly Beribisky, Heather Davidson, and Linda Farmus who assisted with data collection and data entry. 


\section{References}

Aiken, L. S., West, S. G., \& Millsap, R. E. (2008). Doctoral training in statistics, measurement, and methodology in psychology: Replication and extension of Aiken, West, Sechrest, and Reno’s (1990) survey of PhD programs in North America. American Psychologist, 63, 32-50. Doi: http://dx.doi.org/10.1037/0003-066X.63.1.32

Anastasiadou, S. D. (2011). Reliability and validity testing of a new scale for measuring attitudes toward learning statistics with technology. Acta Didactica Napocensia, 4, 1-10.

Bond, M. E., Perkins, S. N., \& Ramirez, C. (2012). Students' perceptions of statistics: An exploration of attitudes, conceptualizations, and content knowledge of statistics. Statistics Education Re-search Journal, 11, 6-25.

Braun, V. \& Clarke, V. (2006). Using thematic analysis in psychology. Qualitative Research in Psychology, 3(2), 77-101, Doi: 10.1191/1478088706qp063oa

Brezavšček, A., Šparl, P., \& Žnidaršič, A. (2017). Factors influencing the behavioural intention to use statistical software: The perspective of the Slovenian students of social sciences. Eurasia Journal of Mathematics, Science and Technology Education, 13, 953-986.

Chiesi, F., \& Primi, C. (2009). Assessing statistics attitudes among college students: Psychometric properties of the Italian version of the Survey of Attitudes Toward Statistics (SATS). Learning and Individual Differences, 19, 309-313.

Conners, F.A., McCown, S. M., \& Roskos-Ewoldsen, B. (1998). Unique challenges in teaching undergraduate statistics. Teaching of Psychology, 25, 40-42. 
Counsell, A., Cribbie, R. A., \& Harlow, L. (2016). Increasing literacy in quantitative methods: The key to the future of Canadian psychology. Canadian Psychology/psychologie canadienne, 57(3), 193-201. Doi: http://dx.doi.org/10.1037/cap0000056

Cronbach, L. J. (1951). Coefficient alpha and the internal structure of tests. Psychometrika, 16, 297-334. http://dx.doi.org/10.1007/BF02310555

Davidson, H., Peters, K., Patton, H., O’Hagan, F. \& Cribbie, R. A. (2019). Statistical software in Canadian university psychology courses. Teaching of Psychology, 46(3), 246-250. Doi: $10.1177 / 0098628319853940$

Dempster, M., \& McCorry, N. K. (2009). The role of previous experience and attitudes toward statistics in statistics assessment outcomes among undergraduate psychology students. Journal of Statistics Education, 17(2). [Online: http://www.amstat.org/publications/jse/v17n2/dempster.html]

Eccles, J. (1983). Expectancies, values, and academic behaviors. In J. T. Spence (Ed.), Achievement and achievement motives: Psychological and sociological approaches (pp. 75-146). San Francisco, CA: W. H. Freeman.

Eccles, J. S. \& Wigfield, A. (2002). Motivational beliefs, values, and goals. Annual Review of Psychology, 53, 109-132.

Emmioğlu, E. S. M. A., \& Capa-Aydin, Y. (2012). Attitudes and achievement in statistics: A meta-analysis study. Statistics Education Research Journal, 11, 95-102.

GAISE College Report ASA Revision Committee. (2016). Guidelines for Assessment and Instruction in Statistics Education College Report. Available at: http://www.amstat.org/education/gaise. 
Gal, I, \& Garfield, J. B. (eds.) (1997). The Assessment Challenge in Statistics Education. Amsterdam: IOS press.

Harlow, L. L., Burkholder, G., \& Morrow, J. (2002). Evaluating attitudes, skill and performance in a learning enhanced quantitative methods course: A structural modeling approach. Structural Equation Modeling Journal, 9(3), 413-430. https://doi.org/10.1207/S15328007SEM0903_6

Harlow, L. L., Burkholder, G., \& Morrow, J. (2006). Engaging students in learning: An application with quantitative psychology. Teaching of Psychology, 33(4), 231-235. https://doi.org/10.1207/s15328023top3304_3

Hernández, O. (2006). Teaching statistics to undergraduate students of the social sciences. In Working Cooperatively in Statistics Education. Proceedings of the 7th International Conference on Teaching Statistics (ICOTS-7).

Hogg, R. V. (1991). Statistical education: Improvements are badly needed. The American Statistician, 45, 342-343.

Jatnika, R. (2015). The effect of SPSS course to students' attitudes toward statistics and achievement in statistics. International Journal of Information and Education Technology, 5, 818-821.

Kubilius, J. (2014). Sharing code. i-Perception, 5(1), 75-8. doi:10.1068/i004ir

McDonald, R. P. (1970). The theoretical foundations of principal factor analysis, canonical actor analysis, and alpha factor analysis. British Journal of Mathematical \& Statistical Psychology, 23, 1-21. http://dx.doi.org/10.1111/j.2044-8317.1970.tb00432.x

McDonald, R. P. (1999). Test theory: A unified approach. Mahwah, NJ: Erlbaum. 
Muenchen, R. A. (2018, March 7). The popularity of data science software. Retrieved from http://r4stats.com/articles/popularity/

Murtonen, M., Olkinuora, E., Tynjälä, P. \& Lehtinen, E. (2008). “Do I need research skills in working life?" University students' motivation and difficulties in quantitative methods courses. Higher Education, 56, 599-612. doi: 10.1007/s10734-008-9113-9

Nolan, M. M., Beran, T. \& Hecker, K. G. (2012). Surveys assessing students' attitudes toward statistics: A systematic review of validity and reliability. Statistics Education Research Journal, 11, 103-123.

Onwuegbuzie, A. J. (2004). Academic procrastination and statistics anxiety. Assessment \& Evaluation in Higher Education, 29, 3-19. doi: 10.1080/0260293042000160384

Onwuegbuzie, A. J. \& Wilson, V. A. (2003) Statistics anxiety: nature, etiology, antecedents, effects and treatments: a comprehensive review of the literature, Teaching in Higher Education, 8, 195-209. doi: 10.1080/1356251032000052447

Rajecki, D. W., Appleby, D., Williams, C. C., Johnson, K., \& Jeschke, M. P. (2005). Statistics can wait: Career plans activity and course preferences of American psychology undergraduates. Psychology Learning \& Teaching, 4, 83-89.

Ramirez, C., Schau, C., \& Emmioglu, E. (2012). The importance of attitudes in statistics education. Statistics Education Research Journal, 11(2), 57-71.

R Core Team (2018). R: A language and environment for statistical computing. R Foundation for Statistical Computing, Vienna, Austria.URL http://www.R-project.org/.

Rode, J. B., \& Ringel, M. M. (2019). Statistical software output in the classroom: A comparison of R and SPSS. Teaching of Psychology, 46(4), 319-327. Doi:

$10.1177 / 0098628319872605$ 
RStudio Team (2018). RStudio: Integrated Development for R. RStudio, Inc., Boston, MA URL http://www.rstudio.com/

Ruggeri, K., Dempster, M., Hanna, D., \& Cleary, C. (2008). Experiences and expectations: The real reason nobody likes stats. Psychology Teaching Review, 14(2), 75-83.

Schau C. (2003). Survey of attitudes toward statistics - 36. Available from CS Consultants, LLC, www.evaluationandstatistics.com. (21 September 2015).

Schau, C., Stevens, J., Dauphinee, T. L. \& Del Vecchio, A. (1995). The development and validation of the Survey of Attitudes Toward Statistics. Educational and Psychological Measurement, 55, 868-875.

Schutz, P.A., Drogosz, L.M., White, V.E., \& Distefano, C. (1998). Prior knowledge, attitude, and strategy use in an introduction to statistics course. Learning and Individual Differences, 10, 291-308.

Sizemore, O. J., \& Lewandowski Jr, G. W. (2009). Learning might not equal liking: Research methods course changes knowledge but not attitudes. Teaching of Psychology, 36(2), 9095. doi: https://doi.org/10.1080/00986280902739727

Stoloff, M., McCarthy, M., Keller, E., Varfolomeeva, V., Lynch, J., Makara, K., Simmons, S., \& Smiley, W. (2010). The undergraduate psychology major: An examination of structure and sequence. Teaching of Psychology, 37, 4-15. doi:10.1080/00986280903426274

Walker, Elizabeth \& Brakke, Karen. (2017). Undergraduate psychology students' efficacy and attitudes across introductory and advanced statistics courses. Scholarship of Teaching and Learning in Psychology, 3, 132-140. Doi: 10.1037/st10000088. 
Ward, B. W. (2013). What's Better-R, SAS®, SPSS $®$, or Stata $®$ ? Thoughts for instructors of statistics and research methods courses. Journal of Applied Social Science, 7(1), 115-120. Doi: $10.1177 / 1936724412450570$

Yechiam, E., Erev, I., \& Parush, A. (2004). Easy first steps and their implication to the use of a mouse-based and a script-based strategy. Journal of Experimental Psychology: Applied, 10, 89-96. 
Table 1

Descriptive Statistics on Attitudes Toward Statistics and R by Student Level

\begin{tabular}{|c|c|c|c|c|c|c|}
\hline & Intro Ugrad (1) & Adv. Ugrad (2) & Postgrad (3) & 1 vs. 2 & 1 vs 3 & $2 v s 3$ \\
\hline & $M(S D)$ & $M(S D)$ & $M(S D)$ & Cohen's d & Cohen's d & Cohen's d \\
\hline T1 SATS Affect & $3.41(1.01)$ & $4.51(1.39)$ & $4.32(0.77)$ & $.91 *$ & $.79 *$ & .14 \\
\hline T1 SATS CogCom & $4.15(1.07)$ & $5.39(0.90)$ & $5.26(0.99)$ & $1.25 *$ & $1.07 *$ & .14 \\
\hline T1 SATS Interest & $4.40(1.26)$ & $5.81(1.07)$ & $5.69(0.96)$ & $1.20 *$ & $1.15^{*}$ & .11 \\
\hline T1 SATS Value & $4.59(1.00)$ & $5.70(1.07)$ & $5.60(0.77)$ & $1.28 *$ & $1.13 *$ & .14 \\
\hline T1 ATST TechCogCom & $3.98(1.39)$ & $4.40(1.37)$ & $4.30(1.40)$ & .31 & .23 & .07 \\
\hline T1 ATST StatsTech & $4.42(1.27)$ & $4.96(1.22)$ & $5.05(1.30)$ & .44 & $.49 *$ & .07 \\
\hline T2 SATS Affect & $3.44(1.28)$ & $4.12(0.96)$ & $4.55(0.71)$ & $.60 *$ & $.90 *$ & .41 \\
\hline T2 SATS CogCom & $4.33(1.17)$ & $5.04(0.61)$ & $5.31(0.83)$ & $.76^{*}$ & $.96^{*}$ & .37 \\
\hline T2 SATS Interest & $3.94(1.59)$ & $5.77(0.98)$ & $5.84(0.80)$ & $1.39 *$ & $1.51 *$ & .08 \\
\hline T2 SATS Value & $4.45(1.28)$ & $5.86(0.80)$ & $5.91(0.68)$ & $1.32 *$ & $1.43 *$ & .07 \\
\hline T2 ATST TechCogCom & $4.06(1.56)$ & $4.76(1.40)$ & $4.69(1.39)$ & .48 & .43 & .05 \\
\hline T2 ATST StatsTech & $4.52(1.66)$ & $5.03(1.65)$ & $5.48(1.19)$ & .31 & $.66^{*}$ & .31 \\
\hline ATR (T2 only) & $4.43(1.63)$ & $5.32(1.38)$ & $5.42(1.11)$ & 0.59 & $0.71 *$ & 0.08 \\
\hline
\end{tabular}

Notes: All scores represent mean scores measuring attitudes toward a particular domain with a possible range of 1-7. Acronyms are as follows: CogComp:

Statistics Cognitive Competence, TechCogCom: Technological cognitive competence, StatsTech: learning Statistics with Technology, ATR: attitudes toward R. Sample sizes are as follows: intro ugrad: 101 at both time points, advanced ugrad: 35 at time 1 and 20 at time 2, postgrad: 48 at time 1 and 40 at time 2 .

Significantly different mean differences at $p<.01$ are marked with an $*$ 
Figure 1. Correlations between the statistical and software attitudinal domains.

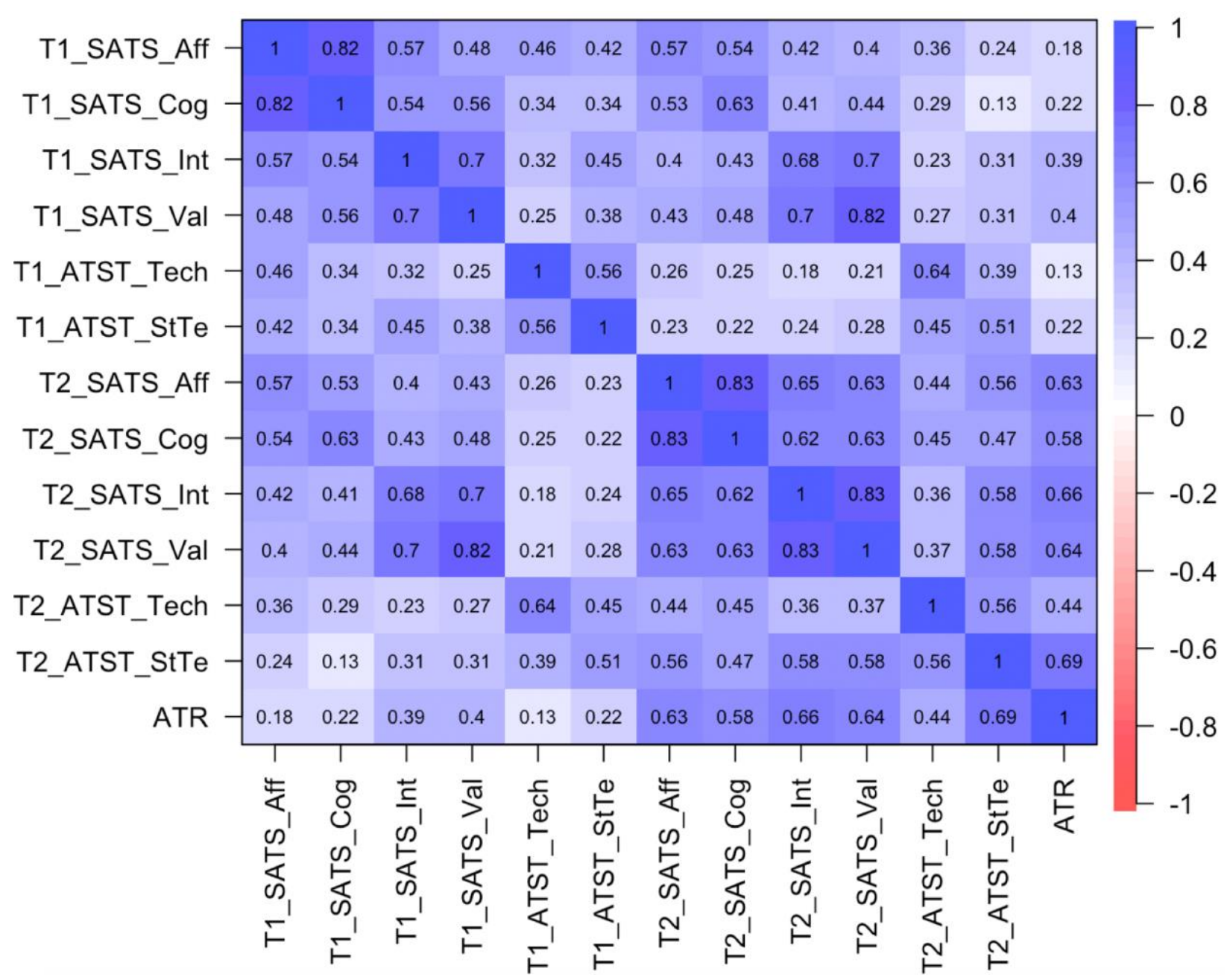

Notes: Correlations are on the full sample (regardless of study level) and included $N=187$ at time 1 and $N=161$ at time 2.

SATS is the Survey on Attitudes Toward Statistics; Aff is affect, Cog is cognitive competence, Int is interest, Val is value; ATST is the Attitudes toward Statistics and Technology Scale; Tech is technological cognitive competence; and StTe is learning statistics with technology; ATR is the attitudes toward R composite score. 
Table 2

Qualitative Analysis: Higher-order Themes

\begin{tabular}{cccc} 
ntotal & $n$ & $n$ & $n$ \\
& intro & adv. & post \\
& ugrad & ugrad & grad \\
\hline
\end{tabular}

1. Comfort and Competence

Comfortable, confidence, competent

Anxious, stressed, lacking competence

2. Instructor and Course Resources

Had positive impact

Had negative impact

3. Enjoyment of R \& Statistics

Enjoyed or liked it

Did not enjoy or like it

4. Degree of Difficulty

$\mathrm{R}$ or Statistics were difficult

R/Statistics Not too difficult

5. Value of Statistics and Software

Somewhat or highly valuable/useful

Not valuable or useful

6. Learning Trajectory

Factors boosted learning/want to continue learning

Factors inhibited learning
67

36

13

18

$16 \quad 11$

2

3

78

47

5

26

27

9

9

9

$\begin{array}{llll}43 & 23 & 5 & 15\end{array}$

52

39

8

5

$52 \quad 36$

10

6

41

22

12

7

49

22

11

16

6

4

0

2

22

7

5

10

19

7

4

8 


\section{Impact of Previous Experience or Expectations}

\section{Positive Impacts}

Negative Impacts

8. Importance of Critical Thinking
8

22

17
4

17

0
0

4

2

Note: the qualitative data came from 134 participants collected at Time 2 only. The 134 participants included 79 undergraduate students in the introductory course, 20 undergraduates taking an advanced statistics course, and 35 postgraduate students. 


\section{Table 3}

Text examples for qualitative themes

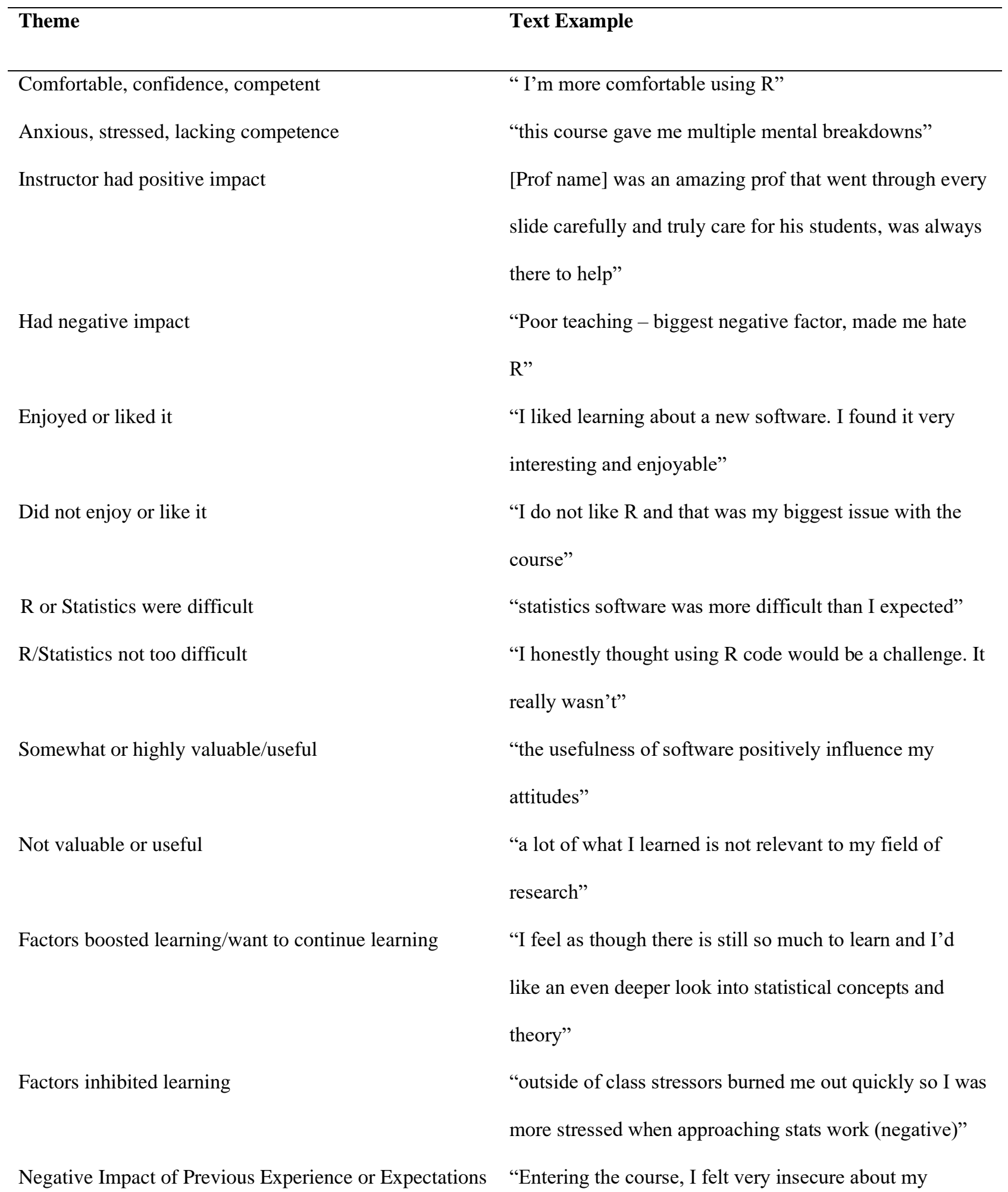


Positive Impact of Previous Experience

Importance of Critical Thinking statistical abilities because this type of thinking does not come naturally to me"

"I previously had a lot of training in R and statistics"

"feeling like there was no "right" answer on our tests

because statistics has a huge gray area....feeling like not

all studies that come out conduct statistics ethically made me kind of sad" 
Table 4

Regression Table with Undergraduate Students' Final Grade as the Outcome Variable

\begin{tabular}{lcccccc}
\hline \multicolumn{1}{c}{ Variable } & $\boldsymbol{B}$ & $\mathbf{9 5 \%} \mathbf{C I}$ & $\boldsymbol{p}$ & $\boldsymbol{\beta}$ & $\boldsymbol{s r} \mathbf{2}$ & $\boldsymbol{r}$ \\
\hline & & & & & & \\
Intercept & 40.85 & $(30.38,51.32)$ & $<.001$ & & & \\
Study Level & 4.60 & $(1.26,7.93)$ & .007 & .312 & .044 & .58 \\
GPA & 2.17 & $(.69,3.65)$ & .005 & .313 & .051 & .61 \\
Used R & -1.09 & $(-7.01,4.83)$ & .714 & -.033 & .001 & .30 \\
R Attitudes & 2.34 & $(0.76,3.91)$ & .004 & .251 & .051 & .47 \\
\hline
\end{tabular}

Notes: $N=93$ undergraduate students, $B$ is the unstandardized regression slope, $\beta$ is the standardized regression slope, $r$ is the raw correlation between the predictor and outcome; $s r 2$ is the semi-partial squared correlation: the unique variance shared with each predictor and the outcome. 


\section{Appendix A}

Attitudes Toward R Questions

I am much more comfortable using R now compared to when I first started using it

Having learned $\mathrm{R}$ will help me analyze my own data in the future

The skills I've learned in $\mathrm{R}$ will be useful for getting a job

While not an expert in R, I am confident that I can find information about $\mathrm{R}$ functions and packages to help me analyze data

I am interested in learning more about data analysis in $\mathrm{R}$

Now that you've finished the course, how would you rate your attitudes about using statistical software like R?

\begin{tabular}{|c|c|c|c|c|c|c|}
\hline $\begin{array}{l}\text { Strongly } \\
\text { disagree }\end{array}$ & & & $\begin{array}{l}\text { Jeither } \\
\text { isagree } \\
\text { or agree }\end{array}$ & & & $\begin{array}{c}\text { Strongly } \\
\text { agree }\end{array}$ \\
\hline 1 & 2 & 3 & 4 & 5 & 6 & 7 \\
\hline 1 & 2 & 3 & 4 & 5 & 6 & 7 \\
\hline 1 & 2 & 3 & 4 & 5 & 6 & 7 \\
\hline 1 & 2 & 3 & 4 & 5 & 6 & 7 \\
\hline 1 & 2 & 3 & 4 & 5 & 6 & 7 \\
\hline $\begin{array}{c}\text { Very } \\
\text { negative }\end{array}$ & & & & & & $\begin{array}{c}\text { Very } \\
\text { positive }\end{array}$ \\
\hline 1 & 2 & 3 & 4 & 5 & 6 & 7 \\
\hline
\end{tabular}




\section{Appendix B}

\section{List of lower order themes from initial thematic coding}

\begin{tabular}{|c|c|c|c|}
\hline Initial Themes & $\begin{array}{c}n \\
\text { intro ugrad }\end{array}$ & $\begin{array}{c}n \\
\text { adv ugrad }\end{array}$ & $\begin{array}{c}n \\
\text { grad }\end{array}$ \\
\hline comfortable with stats & 2 & 1 & 1 \\
\hline comfortable with $\mathrm{r}$ & 3 & 4 & 6 \\
\hline positive instructor/TA & 36 & 2 & 18 \\
\hline negative instructor/TA & 1 & 3 & 5 \\
\hline felt lack of time to learn stats/R & 4 & 1 & 5 \\
\hline slow learning pace allowed for better learning & 0 & 0 & 3 \\
\hline Enjoyed R & 10 & 2 & 5 \\
\hline Enjoyed Stats or the Stats Course & 12 & 2 & 1 \\
\hline Reduced Stress/Did not feel overwhelmed by course material & 8 & 1 & 2 \\
\hline Relative Ease of R & 8 & 4 & 5 \\
\hline Future intentions to learn more R/stats & 5 & 3 & 4 \\
\hline Anxiety/Stress from R by end of course & 2 & 1 & 0 \\
\hline Anxiety/Stress from Stats by end of course & 7 & 0 & 1 \\
\hline Improved attitudes toward stats & 11 & 0 & 3 \\
\hline Improved attitudes toward $\mathrm{R}$ & 10 & 0 & 2 \\
\hline Self competence/efficacy increased & 12 & 4 & 4 \\
\hline self confidence increased & 11 & 3 & 5 \\
\hline felt a lack of understanding/lacked self confidence & 2 & 1 & 2 \\
\hline importance of practical exercises and examples helped learning & 4 & 3 & 2 \\
\hline lack natural math/stats abilities or previous dislike of math & 7 & 0 & 1 \\
\hline Course format (assigns, exams, labs, etc.) was a negative factor & 7 & 6 & 3 \\
\hline Unchanged attitudes & 12 & 3 & 8 \\
\hline Preferred R over other stats software & 0 & 0 & 2 \\
\hline $\begin{array}{l}\text { Felt a need for more experiences/learning to understand the course } \\
\text { concepts well }\end{array}$ & 2 & 2 & 3 \\
\hline Found $\mathrm{R}$ useful or valuable & 9 & 6 & 9 \\
\hline Found stats useful or valuable & 6 & 2 & 4 \\
\hline $\begin{array}{l}\text { Impact of personal engagement/motivation on learning/course } \\
\text { performance }\end{array}$ & 1 & 1 & 3 \\
\hline Did not enjoy/like R & 13 & 1 & 2 \\
\hline Would have preferred other software (not R) & 2 & 1 & 1 \\
\hline Positive impacts of the course resources and outside resources & 6 & 0 & 4 \\
\hline $\mathrm{R}$ was difficult & 15 & 6 & 4 \\
\hline Stats was difficult & 11 & 2 & 1 \\
\hline Mentioned they had relevant previous experience impacting attitudes & 1 & 0 & 4 \\
\hline
\end{tabular}


Mentioned they felt they had a lack of previous experience impacting attitudes

liked/enjoyed $\mathrm{R}$ before taking the course

5

liked/enjoyed stats before taking the course

Course format (assigns, exams, labs, etc.) was a positive factor

Poor technology skills in general impacted their course experiences

Did not think stats was relevant to them or their degree

Bad textbook

Good textbook

Have more negative stats attitudes after taking course

Have more negative $\mathrm{R}$ attitudes after taking course

Noted the ambiguity of statistics

Found stats was not as hard as thought (relatively easier)

stats course or experiences did not meet expectations

disliked lack of software consistency in courses

Reported an "openness" to R or stats

Believes a need for earlier software teaching

reported a more realistic view of statistics after taking course

noted importance of instructor (didn't say if pos or neg for them)

$\mathrm{R}$ was initially difficult (steep learning curve) but got easier

Other students were helpful resources for course

critical thinking about stats is important and influenced their views

$\mathrm{R}$ was frustrating

Disliked statistics

importance of repetition for learning $\mathrm{R}$

Difficulty connecting software and stats concepts

not happy with grade gave negative attitude

statistics was frustrating

attitude toward R may be different from attitude to other software

would have preferred hand calculations to software

$\mathrm{R}$ makes statistics easier

Had negative ideas about stats before coming into the course

External stressors caused issues in the course

Course required for program but otherwise would not be taken

Found less math than expected

R changed how they could do statistics

Found it difficult to get help with $\mathrm{R}$

Based on peer comparisons, they felt negatively about their stats course/experiences
1

0

1

6

4

1

3

6

1

0

6

1

0

1

0

0

0

6

1

0

4

7

1

3

2

1

0

3

2

9

1

2

3

2

1

2

\section{1}

\section{0}

1

\section{1}

1

1

1

1

4

4

2

0

0

0

4

1

3

2

7

3

2

1

0

2

0

1

1

1

0

1

0

0

0

0

0

1 